\title{
O direito ao teatro
}

\section{Resumo}

Este artigo procura formular uma discussão introdutória acerca do direito ao teatro como patrimônio imaterial de uma nação. O artigo apresenta a distinção entre dramaturgia performativa e dramaturgia convencional procurando chamar a atenção da sociedade para o papel de instituições teatrais que deveriam mediar a criação cênica nos diversos planos sociais.

Palavras-chave: Dramaturgia; teatro público; teatro privado

\section{Resume}

Cet article cherche à formuler une discussion d'introduction sur le droit au théâtre en tant que patrimoine immatériel de la nation. L'article présente la distinction entre le drame performatif et le drame conventionel. L'article cherche à attirer l'attention de la société sur le rôle des institutions théâtrales qui devrait faire la médiation de la création scénique dans divers plans sociaux.

Mot clé: Dramaturgie; théâtre public; théatre privé

\section{Abstract}

This article seeks to formulate an introductory discussion about the right to the theater as intangible heritage of a nation. The article presents the distinction between performative drama and drama conventional looking to draw society's attention to the role of theater institutions that should mediate the scenic creation in various social plans.

Keywords: Drama; public theater; private theater

"A distinção entre cultura popular e cultura erudita não deve servir para justificar e manter uma separação iníqua, como se do ponto de vista cultural a sociedade fosse dividida em esferas incomunicáveis, dando lugar a dois tipos incomunicáveis de fruidores. Uma sociedade justa pressupõe o respeito dos direitos humanos, e a fruição da arte e da literatura, em todas as modalidades e em todos os níveis, é um direito inalienável." Antonio Cândido ${ }^{1}$

1. Talvez não seja ainda muito tarde para se repensar essa questão entre nós. Ela pode soar para alguns setores ligados à atividade teatral como demasiadamente idealista ou utópica, ou simplesmente defasada diante das atuais circunstâncias de criação, de produção, e de fruição do teatro numa sociedade neoliberal. De toda forma, parece-me que essa questão está permanentemente colocada, e de tempos em tempos é saudável

\footnotetext{
${ }_{1}^{1}$ Antonio Candido. Vários Escritos, (3ª . ed). São Paulo: Duas Cidades, 1995, pp.262-263.
} 
retornar a ela. Assim, nossa contribuição se apresenta como uma breve introdução ao possível debate sobre o "direito ao teatro", inspirando-se, como já é evidente, no emblemático texto sobre o direito à literatura, escrito pelo professor Antonio Candido em 1988.

2. Nesses últimos doze anos, ao se apreciar a produção teatral brasileira, observa-se um crescente salto em termos quantitativos e qualitativos nos espetáculos oriundos dos principais centros urbanos do país. Respeitando-se a diversidade regional e local, bem como as dificuldades em relação à criação, produção, manutenção e circulação de grupos e coletivos, constata-se um grande número de iniciativas teatrais pelo país afora.

São inúmeros os cursos de teatro, públicos ou privados, que proliferam pelo Brasil. Nas atividades complementares do estudante, do ensino fundamental e médio, seja na rede pública ou na rede particular, a atividade teatral é tão procurada, quando oferecida, quanto as atividades esportivas. Não se deve perder de vista, nesse sentido, o impulso permanente que a produção teledramatúrgica inflama e mobiliza, agindo como um fator de sedução sobre os jovens, atraindo-os a uma condição de candidato a astro televisivo, pela porta do teatro. No mesmo sentido, os projetos sociais mais diversos, nos seus múltiplos segmentos de atuação, se valem da experiência teatral como atividade reabilitadora do espírito num exercício de cidadania e sociabilidade. Enfim, o teatro parece estar em todos os lugares.

No plano de uma atividade mais regular e profissional, para confirmar essa apreciação bastaria uma estatística sobre, por exemplo, o número de festivais de teatro realizados dentro das mais diferentes categorias (profissional, amador, universitário, estudantil etc) por diversas cidades, tanto capitais, quanto cidades do interior. Pode-se fazer numa rápida consulta aos números de inscrições aos editais e fundos de cultura, nas esferas municipal, estadual e federal, admirar também o volume dessa demanda pela realização de projetos na área de artes cênicas. Valeria ainda uma olhada no site, por exemplo, da Cooperativa Paulista de Teatro, que ao longo de trinta anos de existência "conta hoje com cerca de 750 núcleos e 3.800 associados, respondendo pela maior parte da produção artística teatral do Estado [de São Paulo], contando com companhias das mais diversas linguagens e com amplo reconhecimento de sua excelência cultural" 2 .

As casas de espetáculos, sobretudo os teatros privados estabelecidos no eixo Rio-São Paulo, desfrutam hoje de instalações e maquinaria que permitem a encenação de espetáculos que outrora não eram possíveis de serem realizados, por conta da incompati-

\footnotetext{
${ }^{2}$ http://www.cooperativadeteatro.com.br/2010/ Acessado em 02 de março de 2012.
} 
bilidade entre o estado de certos edifícios teatrais e a tecnologia envolvida nesses mesmos espetáculos, sobretudo aqueles oriundos dos teatros da Broadway. Apesar do eixo Rio-São Paulo manter sua hegemonia histórica, em relação à concentração da produção teatral, reconhece-se um esforço de descentralização. Igualmente, em outros centros urbanos, observa-se uma intensificação, tanto em relação ao comportamento criativo dos diversos grupos e coletivos, que buscam manter uma atividade teatral de forma sistemática, quanto dos modos de produção que se vão tentando criar ou aprimorar.

A circulação de grupos, companhias, e coletivos tem sido relativamente estimulada pela mediação de instituições públicas e privadas. No passado recente houve a importante ação coordenada pela FUNARTE, com seu Projeto Mambembão, implementado no final da década de 1970, finalizado em 1980, que foi recentemente reabilitado. Desta forma, parte significativa da produção teatral brasileira pode ser descoberta, reciprocamente, de norte a sul. Hoje, há projetos similares fomentados pelo Itaú Cultural, ou o exemplo do já consagrado "Palco Giratório", idealizado e realizado pelo Departamento Nacional do SESC que permite, igualmente, o deslocamento de grupos e coletivos teatrais, os quais se apresentam em pequenas temporadas ao termo de longas turnês pelo interior do Brasil ${ }^{3}$.

Alia-se a esse quadro toda uma produção crítica em escala nacional. E se por um lado consta-se uma retração crescente da expressão e do lugar da crítica teatral nos principais jornais de circulação nacional, por outro lado, a presença de um exuberante volume de críticas e comentários se faz presente na internet. Blogs e sites mais ou menos especializados fazem a descrição e a crônica dos espetáculos em cartaz, prática crescente que se multiplica, graças às redes sociais e a abrangência da internet. Tem-se nessa mídia uma espécie de interação e/ou expressão da impressão da comunidade sobre essas produções ${ }^{4}$. Advém das universidades uma colaboração inestimável, com a publicação de diversos periódicos especializados, ao mesmo tempo em que a reflexão sobre a prática e a teoria do teatro se manifesta em publicações específicas e de circulação dirigida. Outras são as publicações geradas no âmbito dos

\footnotetext{
${ }^{3}$ Sobre o Projeto Mambembão e sobre o Palco Giratório, consulte-se Sidnei Cruz: Palco Giratório: uma difusão caleidoscópica das artes cênicas. Fortaleza, SESC/Ceará, 2009.

${ }^{4}$ Consulte-se a esse respeito o abrangente trabalho de Helena Maria Mello: Critica teatral brasileira na era digital (dissertação de mestrado), no Programa de Pós Graduação em Artes Cênicas da UFRGS, 2010. Na internet o numero de blogs e de sites que comentam com maior ou menor profundidade a atividade teatral não para de crescer. Pode-se destacar deste grande conjunto uma publicação como a Questão de Crítica: revista eletrônica de críticas e estudos teatrais http://www.questaodecritica.com.br/ ou o site Antaprofana http://www.antaprofana.com.br/home.asp
} 
próprios grupos e coletivos teatrais, os quais também implementam uma produção editorial com o intuito de afirmar as suas particularidades éticas e estéticas, disponibilizando à sociedade seus processos criativos, os bastidores da criação teatral. Dentre essas publicações se inclui com destaque os programas dos seus espetáculos. Teoria e prática deram-se as mãos ${ }^{5}$.

Percebemos que essas pequenas publicações, os programas de espetáculos, deixam de ser, unicamente, um produto de divulgação, de caráter informativo ou publicitário, para se transformar em uma peça chave para os estudos sobre os propósitos da cena teatral: um objeto de reflexão sobre o ato criativo; o processo de elaboração da obra e a sugestão de pistas para o ato de fruição de uma encenação teatral. O programa pode ser considerado assim como uma fonte primária, que ao ser interrogada pode nos revelar importantes elementos para contextualização histórica dos espetáculos, bem como as ambições artísticas e ideológicas dos coletivos, sem perder de vista a relação que se quer estabelecer entre agentes criativos e seu público. Como temos nos dedicado à pesquisa sobre os programas de espetáculos, podemos ressaltar, dentre outros aspectos, que ao analisar esses opúsculos, um sintoma se multiplica a olhos vistos: a mutação que vem sofrendo o termo dramaturgia, ao menos na cena brasileira ${ }^{6}$.

3. Como se percebe pela leitura desses programas de espetáculos e na apreciação de grande parte das encenações contemporâneas, o termo dramaturgia tem sido empregado, na atualidade, de forma diversa do que fora no passado. Como

\footnotetext{
${ }^{5}$ Em relação às principais revistas universitárias oriundas dos departamentos e dos programas de pós-graduação em teatro ou em artes cênicas, podemos destacar: Repertório (PPGAC/UFBA); Sala Preta (PPGT/USP); Percevejo (PPGT/ UNIRIO); Urdimento (PPGT/UDESC); Cena (PPGAC/UFRGS); Ouvirover (PPGA/UFU); Revista da FAP (PR); Revista Moringa (Decen/UFPB). Quanto às publicações oriundas dos grupos e coletivos, tem-se: Subtexto (Grupo Galpão/ MG); Vintém (Cia do Latão/SP) Folhetim (Teatro do Pequeno Gesto/RJ); Cadernos do Lume (Lume/SP); Cadernos do Folias (Folias D'Arte/SP), entre outras publicações. Como se percebe, existe aqui material para uma importante discussão, sobre a qual não nos deteremos neste instante, acerca da diminuição do espaço e da recorrência da presença da critica teatral nos principais jornais e veículos de comunicação de massa no país, bem como o aumento de um outro tipo de produção que registra, descreve, critica e analisa a produção cênica brasileira na internet.

${ }^{6}$ Alguns resultados parciais sobre nosso trabalho podem ser apreciados em: TORRES NETO, Walter Lima. "Programas de teatro: traços de uma experiência criativa". In: Comunicação apresentada no VI Congresso de Pesquisa e Pós-Graduação em Artes Cênicas da ABRACE. São Paulo, 2010. Disponível em: http://portalabrace. org/vicongresso/historia/Walter_Lima_Torres_Neto_Programas_de_Teatro.pdf; RIBEIRO, Felipe M. Bachmann e TORRES NETO, Walter Lima. "O programa de teatro: um novo pacto estético cultural?". Comunicação apresentada no 1․ CIELLI. Colóquio Internacional de Estudos Lingüísticos e Literários da Universidade Estadual de Maringá UEM. Realizado de 9 à 11 de junho de 2010 em Maringá, Paraná. In: Anais do Colóquio: ANAIS - ISSN 2177-6350 http://www.cielli.com.br/downloads/696.pdf e por fim: RIBEIRO, Felipe M. Bachmann e TORRES NETO, Walter Lima. “- Olha ô programa da peça!”. In: Urdimento, n 16. Florianópolis: PPGT/CEART/UDESC, junho 2011, pp. 139-151. http://www.ceart.udesc.br/ppgt/urdimento/2011/index_16.html
} 
se sabe, desde o século XIX, o termo dramaturgia se consolidou deixando de ser, unicamente, um conjunto de preceitos e regras de valores universais para significar, simplesmente, a "arte ou técnica da composição dramatúrgica". É certo que se trata de um termo complexo que na sua trajetória esteve associado a diferentes dogmas e restrições, no tocante à eficácia dessa mesma arte e/ou técnica de composição. Atualmente, porém, o termo pode ser compreendido também como a instrumentalização da passagem do texto à cena, a transformação de uma obra dramática em obra cênica, sem querer ser, no entanto, sinônimo de encenação, mas certamente de texto cênico.

Nos dias que correm, não só no Brasil, o termo vem sendo empregado por diversos artistas e coletivos teatrais acompanhado de complementos tais como: "dramaturgia do corpo"; "dramaturgia da luz"; "dramaturgia da cena"; "dramaturgia do ator"; "dramaturgia do figurino", "dramaturgia da voz," entre tantas outras designações, além do emblemático "dramaturgia performativa". Este é um sintoma significativo que deve ser apreciado e problematizado.

Esse sintoma sugere uma luta, a disputa pelo poder hegemônico no processo criativo visando à gestação, organização e realização material de uma cena. Da mesma forma, o sintoma pode escamotear uma falsa horizontalidade, que por vezes emana do discurso dos próprios processos criativos. Trata-se de uma contenda, que acontece no interior do campo da própria linguagem teatral, na veiculação através de seus signos de conteúdos e formas singulares julgadas mais ou menos adequadas para expressão de uma substância sócia teatralizada. Trata-se de uma luta entre os elementos que outrora constituíam o significado da cena moderna, apontado pelo olhar, por vezes despótico e autoritário, do moderno diretor teatral. Hoje, a luta se dá pelo protagonismo, em termos criativos, deste ou daquele elemento constituinte da encenação teatral convencional. Esses elementos, cada qual com suas características e dinâmicas criativas internas, acabaram condicionando a criação cênica contemporânea. O "teatro de linguagem" ou dito "de pesquisa", herdeiro do teatro de vanguarda, ou o chamado "teatro processual", bem como os processos criativos ditos colaborativos são em grande parte o ambiente de onde aflora essa "nova dramaturgia". Ao contrário do que foi no passado, "arte ou técnica da composição dramatúrgica", a dramaturgia passa a ser compreendida como um campo semântico de tensões criativas, aberto e permeável às mais distintas apropriações em termos de significados e significantes. 
O termo dramaturgia, sempre seguido de um complemento, faz pensar, certamente, sobre as novas lógicas criativas, as estratégias para produção de sentido particular sobre a cena. Isto nos remete às novas atitudes e dinâmicas de trabalho referentes aos agentes criativos, que criam, independentes de uma matriz dramatúrgica, uma peça de teatro ou um texto escrito por um autor teatral, que poderia sugerir um valor universal. E para legitimar-se nessa luta pelo poder de protagonizar, o processo criativo, a dramaturgia "disto" ou "daquilo" visa, na encenação, em sua grande maioria, não mais à apresentação de narrativas representacionais, com atores em estado de interpretação, mas sim a uma cena não representacional. Paradoxalmente, nessa operação de ressignificação do termo dramaturgia, no tempo presente, o que dela é substancialmente subtraído é a noção de representação que sempre foi um atributo intrínseco à atividade teatral, antes das experiências entendidas como pós-dramáticas. Isto nos permite afirmar que pode, nos tempos que correm, para determinadas correntes criativas, haver dramaturgia sem que haja necessariamente representação.

Aliada a essa negação da representação, se estabelece uma genealogia de processos e construções cênicas que expressam ideias e conceitos; promovem experimentos sensoriais; visam à exibição de experiências de vida, as mais inauditas; apropriam-se de resíduos biográficos dos próprios agentes criativos; entre outros procedimentos. Os agentes criativos contemporâneos buscaram o auxílio de um termo consagrado, o termo dramaturgia, para que fosse possível estabelecer uma mínima coerência criativa, uma conexão processual, uma lógica atribuída a um novo discurso teatral híbrido expresso em cena sem a sustentação de uma dramaturgia convencional.

O emprego do termo dramaturgia sobressai de maneira a querer nos sinalizar que há uma forma de anotação (ou seria uma partitura?), minimamente sistematizada, cujo conteúdo é veiculado por meio da expressão destes signos da cena. Não é mais a cena que se emancipa da literatura, isto é, da dramaturgia, mas são os elementos constituintes da cena que se emancipam da própria cena. Como dissemos, agora sob nova direção, graças a um novo olhar para a função social do teatro, esses elementos expressam sentidos particulares por meio de uma outra organização dramatúrgica específica, e se liberam assim, eles próprios, do jugo da encenação convencional. Essa dinâmica criativa, que gera uma dramaturgia performativa, passa a ser o fio condutor do processo que se dá a ver numa etapa de seu permanente work in progress, quando da apresentação deste "experimento cênico" ao público. 
4. Durante os anos 1940, no momento do segundo pós-guerra, a noção de Teatro Nacional Popular ganhou força, aliada ao esforço de reconstrução das nações envolvidas no conflito mundial. A essa situação seguiu-se a constituição de uma política intervencionista dos Estados europeus que fomentou a criação ou reconstrução dos Teatros Nacionais — drama, ópera e balé —. Bertolt Brecht e Helene Weigel se instalaram em Berlim Leste e criaram o Berliner Ensemble em 1949. Em Milão, Paolo Grassi e Giorgio Strehler construíram literalmente seu prédio, o edifício do Piccolo Teatro de Milano, inaugurado em 1947. Na França, o TNP passou a ser dirigido por Jean Vilar (1951-1963), após convite feito pelo governo. Já desde 1947 esse diretor vinha trabaIhando em prol da descentralização da atividade teatral em função do Festival de Arte Dramática de Avignon, que ele próprio ajudara a criar. Na Inglaterra, país onde o teatro sempre teve uma tendência fortemente ligada ao entretenimento comercial, estabelece-se de pronto a valorização de um repertório que retoma os grandes clássicos elisabetanos. Tratava-se de um movimento geral tanto a leste quanto a oeste de Berlim que passava a ser uma espécie de frágil ponto de equilíbrio entre as nações europeias após o fim do conflito e o restabelecimento das fronteiras. Pode-se concluir desse movimento que a identidade das nações, como um projeto coletivo, se dava também graças ao fortalecimento de instituições teatrais, com ações e programas destinados a estabelecer uma grande duração para seus objetivos. Essas instituições ainda hoje existem e sobrevivem, apesar das contradições e dificuldades dos tempos neoliberais e das oscilações das políticas públicas na área teatral.

No caso do Brasil, sempre atento às experiências estrangeiras na tentativa de oportunizar uma política de Estado para o teatro nacional, constata-se que tal experiência teve lugar na esfera federal, com a implementação de companhias estáveis de repertório coordenadas pelo antigo Serviço Nacional de Teatro, criado no final da década de 1940: Comédia Brasileira (1940-1945), Companhia Dramática Nacional (1953-1954), Teatro Nacional de Comédia (1956-1967). Não só em termos nacionais, mas igualmente no âmbito dos estados, do ponto de vista ideológico, pode-se salientar iniciativas, tanto particulares como a de um idealista como Haroldo Serra, em Fortaleza, primeiro com o Teatro Experimental de Arte em 1952 e em seguida com o conjunto artístico Comédia Cearense; quanto a iniciativas públicas, houve o exemplo do Teatro de Comédia do Paraná (TCP), companhia oficial do estado, cuja fase inicial 1963-1968, se deu sob a direção de Cláudio Correia e Castro. Pode-se notar, em relação às insti- 
tuições estrangeiras, que elas existem até hoje, apesar do colapso que vivem, e que as iniciativas brasileiras não perduraram muito tempo. Um aspecto bastante plausível para esse desinteresse reside no fato de que o teatro era uma voz de real expressão e combate à ditadura. O governo militar, com o controle do Estado, que durou do golpe de 1964 até a eleição de Tancredo Neves em 1985, pouco se interessaria em incentivar e promover esse teatro de "elite para todos" com algum sentido ideológico, e dificilmente se relacionaria com os artistas de teatro, que naturalmente pensavam diferente, não só em relação ao plano estético, mas sobretudo em relação ao plano político?.

Todas essas iniciativas de constituição de instituições teatrais sedimentadas, tanto estrangeiras mais longevas, quanto as brasileiras abortadas, tinham por princípio a fórmula cunhada por Jean Vilar citada acima,"um teatro de elite para todos”. Isto é, uma busca pela disponibilização à população de uma produção teatral de alta qualidade artística e cultural nos trabalhos encenados, os quais deveriam ser acessíveis a todos os segmentos sociais, sem discriminação cultural ou econômica. Pensava-se em oportunizar naquele momento a permanência de um repertório por meio do qual o cidadão-espectador pudesse se formar e se reconhecer inserido num processo histórico de cunho coletivo. Neste sentido, é importante também lembrar das contradições vivenciadas pelo TNP, sob o comando de Jean Vilar, na França.

Desde o seu início, o TNP teve dificuldades em superar problemas como o de deslocar o espetáculo ou de levar ao teatro o trabalhador e o operário para desfrutarem da experiência teatral. Ao longo desse grande programa de formação de um novo público, diversos fatores tais como a jornada de trabalho extenuante e as dificuldades em desmistificar a própria cerimônia da ida ao teatro comprometeram o êxito desta tentativa de popularização ${ }^{8}$.

O teatro de arte de contornos eruditos sempre foi uma atividade associada à elite, não só no Brasil. Lembre-se do exemplo entre nós de uma empresa de capital privado como o Teatro Brasileiro de Comédias, criada em 1948 pelo empresário Franco Zampari, em São Paulo. Mas independentemente das oposições entre teatro erudito e teatro popular, manifestas, por exemplo, numa oposição a princípio simplista entre

\footnotetext{
7 Sobre essa questão consulte-se: Silvana Garcia: Teatro da Militância. São Paulo, Editora Perspectiva, 1990 e Edélcio Mostaço: Teatro e Política: Arena, Oficina e Opinião, São Paulo, Proposta Editorial \& Secretaria de Estado e Cultura de SP, 1982

${ }^{8}$ A questão de um teatro de arte desenvolvido no continente europeu pode ser apreciada no ensaio crítico de Jean-François Dusigne: Le Théâtre d'Art: aventure européenne du XXè siècle. Paris. Editions Théatreles, 1997.
} 
a programação de uma empresa como o TBC e a programação de uma empresa de Teatro de Revistas, o que nos chama atenção é a substância social figurada na permanência de uma dramaturgia veiculada por essas duas tendências.

Apesar do fim precoce das instituições brasileiras, o que esteve e continua em jogo, graças à permanência ao menos das instituições estrangeiras, é o trabalho teatral que se mantém afirmativo na oportunização à sociedade de um repertório nacional e/ ou estrangeiro. O público-cidadão tem o direito de conhecer esse repertório e viver a experiência imaginária de se relacionar com essa substância histórico-social, associando-a a sua realidade contemporânea.

5. O sistema de produção teatral brasileiro, nestes últimos vinte anos, ganhou contornos específicos e bem distintos do perfil europeu ou estadunidense. Graças às atuais leis de incentivo, permite-se o financiamento de arrojados empreendimentos econômicos na área das artes cênicas. O Brasil acabou por implementar um sistema híbrido de produção. Exemplos recentes foram os espetáculos do Cirque du Soleil; musicais como Um violinista no telhado ou Priscilla, a rainha do deserto. Nestes casos, o modo de produção brasileiro, implementado pelo Estado, financia o benefício do lucro econômico de empresas de produções artísticas e entretenimento, na realização de espetáculos-empreedimentos, de forte apelo comercial e inegável valor simbólico do ponto de vista de uma lógica capitalista, que só enfatiza a mundialização de produtos da indústria cultural. Contrapõe-se ao preço dos ingressos dessa categoria de espetáculos que, assumidamente, visam ao lucro de uma bilheteria, os ingressos do tipo a $\mathrm{R} \$ 1,99$ ou ingressos trocados por $1 \mathrm{Kg}$ de alimento não perecível, produzidos por coletivos, grupos e companhias nativas que pressupõem a veiculação de valores opostos ou mais locais e particulares em suas produções, cujo modelo de produção também é outro.

A desigualdade social e sobretudo econômica não consegue ser combatida dentro desta fórmula. Porque a desigualdade socioeconômica está associada à desigualdade educacional e cultural, e, sobretudo, às divergências no tocante ao que se entende por cultura e produção originária da indústria cultural. Pode-se pressupor que, em parte, essa desigualdade poderia ser corrigida se houvesse a presença dessas instituições mediadoras como as lembradas acima no plano estrangeiro.

Essas instituições permitiriam a manutenção e atualização de um repertório nacional e estrangeiro. Um repertório que é direito do cidadão-espectador brasileiro conhecer para poder se reconhecer - ou para julgá-lo superado - localmente e nacio- 
nalmente. Estaríamos diante de um duplo desafio. $O$ desafio de assegurar o direito das gerações atuais e futuras de conhecerem o repertório teatral brasileiro e estrangeiro e o desafio, para os artistas de teatro, de encenarem esse mesmo repertório considerando a mentalidade de hoje e as disposições estéticas e artísticas vigentes na contemporaneidade. Não se trata de pleitear encenações museológicas!

No caso do repertório nacional, que atravessa séculos, constata-se a presença de textos instigantes e provocadores como os de José de Anchieta, que relido pelos estudos da etnocenologia ou pelas teorias da performance ganharia outra dimensão. $O$ repertório teatral brasileiro do século XIX é muito extenso, irregular e surpreendente. Ele registra obras com forte impacto social como O demônio familiar, de José de Alencar, ou Como se fazia um deputado, de França Júnior, para lembrar de dois títulos dos mais óbvios, que desde seus enunciados sinalizam uma relação direta com questões da atualidade. Isso sem falar em Martins Pena, autor de grande capricho na carpintaria teatral, que com as relações sociais presentes em suas comédias permite uma identificação com qualquer cidade brasileira que tenha vivido o processo cultural entre o Brasil colonial e Imperial. Ou ainda, o que dizer sobre a estranheza da obra de Qorpo-Santo, que já inspirou tantos estudos especulativos visando a investigar sua gênese?

Isso sem falar no repertório do século XX, cuja primeira e segunda metade são tão distintas em termos estéticos quanto ideológicos, mas que apresentam grandes quadros e mosaicos da realidade brasileira, com autores de variados estilos e gêneros. Da reprodutibilidade de um gênero como o da comédia de costumes e do teatro musical nacional às experiências de linguagem propostas por Oswald de Andrade. Os quatro nomes emblemáticos do moderno teatro nacional (Ariano Suassuna, Nelson Rodrigues, Jorge Andrade e Dias Gomes) que dominam o início dessa segunda metade do século XX, deveriam poder ter suas obras em cartaz, circulando pelo Brasil, tamanha a força de valores que emanam de suas peças. Esse seria um repertório chave para apresentar ao cidadão-espectador o processo de modernização do país entre rural / provinciano e citadino / urbanizado. E ainda Oduvaldo Vianna Filho, Plínio Marcos e Gianfrancesco Guarnieri por meio dos quais a realidade sociopolítica é expressa de forma a estabelecer uma resistência ao regime militar ditatorial. Evidentemente, que nos limites desta breve introdução, estamos lembrando dos nomes mais emblemáticos de nossa dramaturgia, o que não quer dizer que os autores que não foram lembrados aqui não mereçam a mesma distinção. 
Com essa ênfase no direito de se assistir a um repertório dramatúrgico, que certamente precisa ser enriquecido pela leitura atualizada de encenações vigorosas, não se deseja desprezar a expressão teatral contemporânea. Tanto a nova "dramaturgia performativa", como tentamos descrever acima, quanto a "dramaturgia convencional" mediada por uma encenação, devem ser o objeto de uma política de Estado, não só o esforço isolado de grupos e coletivos. Só uma política de Estado pode assegurar a permanência desse patrimônio imaterial nas esferas municipal, estadual e federal. E que, sobretudo, esse repertório possa ser revisitado de tempos em tempos alternado com o teatro estrangeiro.

Não há dificuldades em se conciliar as duas noções de dramaturgia a que aludimos anteriormente. O que não se deveria incentivar é a exclusão de uma categoria pela outra, pois quem perde é o espectador-cidadão, a quem se omite as formas simbólicas manifestas pelo teatro. E, neste sentido, dada a irregularidade e a complexidade de nossas plateias regionais e locais, parece-nos que somente com instituições devidamente enraizadas na trama da vida teatral é que alcançaríamos algum tipo de sucesso em prol de estratégias que promovessem o direito do cidadão-espectador ao teatro.

Caso contrário, o cidadão estará fadado a se submeter, inadvertidamente, às incertezas das experiências performativas de teor autorreferencial, que podem custar 1,99 o ingresso subsidiado; ou se deleitar na total alienação ao parcelar, no seu cartão de crédito, o valor do ingresso, também subsidiado, para assistir um espetáculo do tipo franchising da Broadway.

\section{Referências bibliográficas}

CARLSON, Marvin: Performance: uma introdução crítica, (trad. Thais Flores N. Diniz e Maria Antonieta Pereira). Belo Horizonte: Editora da UFMG, 2010.

CARLSON, Marvin: Teorias do teatro, (trad. Gilson César C. de Sousa). São Paulo: UNESP, 1995.

GUENOUN, Denis: O teatro é necessário?, (trad. Fátima Saadi). São Paulo: Editora Perspectiva, 2004.

SARRAZAC, Jean-Pierre: Critique du théâtre: de l'utopie au désenchantement. Belfort: Editions Circé, 2000. 